\title{
Quatro notas sobre uma oficina em Goa
}

\author{
Alexandre Calado
}
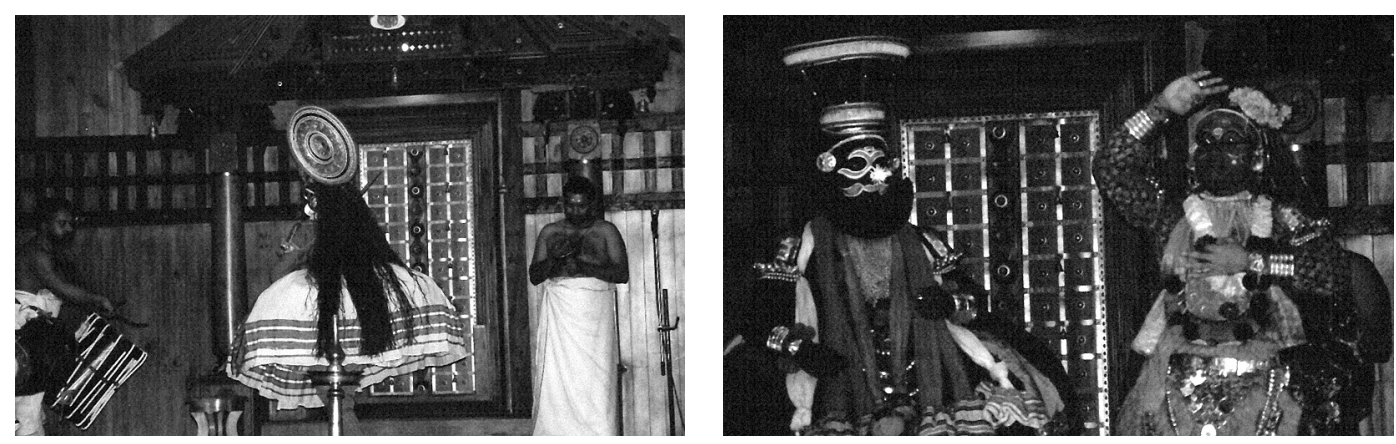

$<5>6$

Mahabharata,

enc. Irathakulangara Rama Varrior,

Kerala Kathakali Center (Kathakalimandapam), Fort Kochi, 2008, fot. Anabela Mendes.

1.

Goa, do quarto onde escrevo, é uma loja de bebidas, na

Av. Corifeu de Azevedo Marques, duas ruas abaixo de onde moro há umas semanas, em São Paulo. Dia 1 de Abril faz cerca de quatro meses que facilitei com a minha amiga actriz Sandra Hung uma oficina de movimento em Pangim. Revejo notas, relembro, reflicto. Goa, para mim, começou como a terra de onde vieram os pais da Susana e do Roberto, os do Rui, a mãe da Beatriz e da Cláudia. E logo também a comida, ora caseira, ora de um dos muitos restaurantes que se encontram espalhados por toda a Lisboa - lassi de manga, caril de camarão com molho de coco, cheque-cheque de caranguejo, a chamuça estaladiça. Um moço que trabalha numa produtora local de televisão pergunta-me - "Consegue sentir o aroma da canela sob o anis estrelado e o chili verde?" - estamos a almoçar numa viela do Bairro das Fontainhas, em Pangim. Aqui, em São Paulo, como em outras partes do globo, a Índia invade as casas, de segunda a sábado, no horário nobre e em versão digest. No letreiro por cima da loja lê-se

"Bebidas nacionais e importadas." Entro na loja, estamos ainda em Março. Mais de metade do espaço está ocupado com garrafas desse sumo fermentado de uva que hoje é produzido nos quatro cantos do mundo - Austrália, Chile, Portugal, Argentina, França, Itália, Califórnia, sou informado que o Uruguai tem vinhos muito bons. A possibilidade de oferecer esta oficina de movimento surgiu no âmbito de um projecto sobre viagens, um projecto marcado por movimentos interculturais, derivas transcontinentais. Estou em Goa, na loja de bebidas; o rapaz que trabalha aqui fala-me das preferências nacionais e diz-me que o brasileiro gosta de vinhos frutados e com aromas de baunilha.

A dado momento, eu e a Sandra decidimos trabalhar na oficina uma qualidade de tempo, um espectro de estados tensionais e um imaginário influenciados pelo butoh - o butoh partilha com a enofilia e com a gastronomia 0 prazer da sensação detalhada.

2.

2.

Caminho ao longo da praia, numa tarde de Novembro. Do caderno, leio: 0 que posso partilhar? Que tipo de espaço de criação é possível? Como engendrar uma prática crítica e consciente? Exmouth é uma pequena cidade balnear, no sudoeste da Inglaterra, que desce para o mar por ruas estreitas, pontuada por um farol altaneiro; pequenos casinos, carrosséis e barraquinhas de fish' $n$ 'ships bordejam a costa. Observo as pessoas que caminham no calçadão, jovens casais, pequenos grupos de idosos, um senhor que passeia com um cão - reflicto sobre experiências que moldam as geologias do corpo, debruço-me sobre a tectónica. Lembro que o butoh que há anos conheci em Almada, com a bailarina e pedagoga Maria Reis Lima, também perto do mar, continua a mover o meu corpo. Sinto que é honesto propor uma oficina sobre algo que é importante para mim e que acredito poder ser estimulante, escrevo por correio electrónico à Sandra. Desço para a praia, caminho, pouca areia e muito cascalho fazem do meu andar um titubear irregular - negoceio cada passo com a gravidade; o primeiro elemento da oficina em Pangim. Aqui ao lado, em Exeter, onde vim estudar Intercultural Performer Training, houve uma oficina de butoh, dirigida por uma moça australiana que agora reside no Reino Unido; lembrámos aí a influência decisiva da dança expressionista de Mary Wigman na génese do butoh. Assumo que trabalharei um butoh, desconheço tão pouco o exacto significado do termo: designação para dança ocidental, no Japão, referência a saudação imperial na qual se bate com os pés no chão; mas é este um dos fascínios, palavra a descobrir, género a inventar. Um primeiro elemento: andar, ver com os pés, ser puxado por um fio três dedos abaixo do umbigo. Continuo caminhando, encolhem as pessoas e as casas à medida que me afasto, eu mesmo vou ficando menor junto às falésias, na borda do mar imenso, sob o céu povoado de nuvens. A natureza afirma o seu carácter irredutivel, saio do centro, as forças que dinamizam
Alexandre Calado é licenciado em Engenharia do Ambiente, Faculdade de Ciência e Tecnologia Universidade Nova de Lisboa, Mestre em História e Filosofia da Ciência, pela mesma Universidade, $\mathrm{e}$

Licenciado em Teatro ramo Educação pela Escola Superior de Teatro e Cinema. Prepara o seu doutoramento em Teatro e Educação na Universidade de S. Paulo. É ainda actor, encenador $\mathrm{e}$ investigador. 


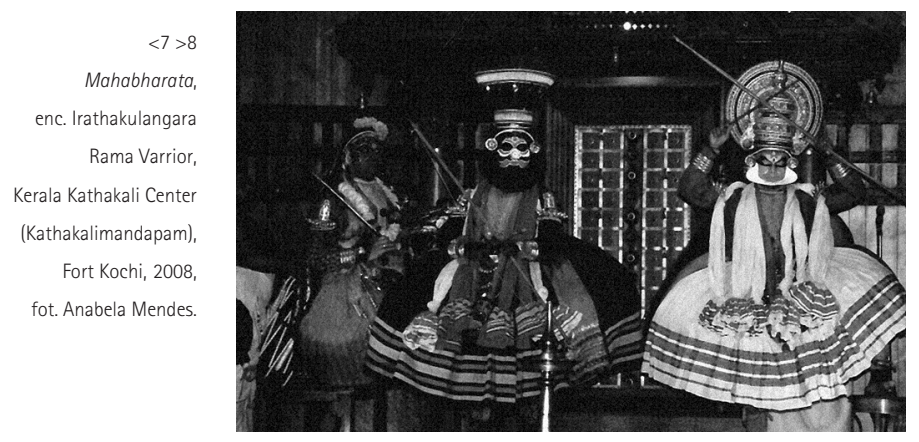

a matéria conquistam o plano, perco a certeza das fronteiras do corpo, cresce-me água na boca. Um segundo elemento do programa: os olhos fixos longe no horizonte, o olhar mergulhado para dentro do corpo. Hijikata Tatsumi é considerado um dos fundadores do butoh quando cunhou o termo ankoku buyo para o seu movimento vindo do lado da mais profunda escuridão humana, paisagem interior projectada no espaço, dança do avesso. 0 movimento no teatro trata da tensão entre um corpo imaginado e um corpo concreto - um corpo de sensação. Continuo a andar os meus olhos perscrutam as pequenas pedras roladas pelo mar, depois paro e fico suspenso a contemplar o espaço aquoso imenso. Desaba a meu lado um pedaço da encosta barrenta, súbito som leitoso; babo - terceiro elemento da oficina em Goa. Aqui ao lado, Exeter, vi a alegria com que os meus colegas abraçaram o butoh como uma clareira de possibilidades infinitas, escrevo à Sandra por correio electrónico. Um terceiro elemento: cair e levantar, lentamente, ser puxado por um fio no topo da cabeça, empurrar o chão, vencer a gravidade. 0 trabalho é real, o corpo transforma-se. Sinto o butoh enraizado no meu corpo, magma deslocando-se, pressionando vapores, metamorfoseando a minha paisagem interior. Decidimos por correio electrónico que ambos participaremos dos exercicios propostos, faremos junto com os formandos, corpos que formam corpos. Apanho na praia três pequenas pedras roladas pelo mar.

\section{3.}

Amanhece domingo, em meados de Dezembro, a lua cheia ainda não se escondeu completamente, recolhem-se as cadeiras de plástico, arrumam-se os precários iodines e o equipamento de som, os actores desmaquilham-se depois da apresentação que durou toda a noite. Palakkad é uma cidade e o nome de um município do Estado de Kerala, rumámos para sul de Goa, fica numa depressão natural que liga este Estado ao de Tamil Nadu, pelo leste.

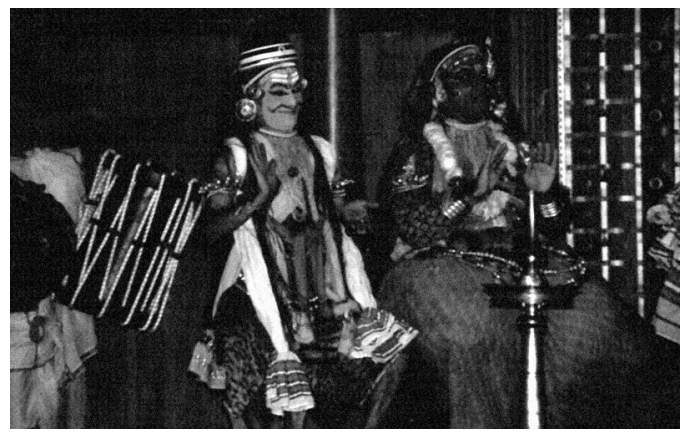

Uma experiência inesquecivel - a céu aberto, mais de dez horas sem interrupção, sonoridades gritantes, o colorido dos figurinos e pinturas faciais, uma exuberância ao mesmo tempo rigorosa e coloquial dos actores-bailarinos, o público que conversa e dorme, que vem e que vai, na plateia, no bar, o movimento na sala onde se preparam os intérpretes. Os deuses aparecem na terra. Eu e a Sandra estamos exaustos. "No kathakali é preciso ter pernas fortes" - o actor e pedagogo Balasubramaniam dirige uma aula aberta, mostra-nos disciplinas rítmicas com os pés que lembram o método de treino desenvolvido por Suzuki Tadashi, exercicios com os olhos, dias antes, na capital Trivandrum. 0 professor marca os tempos percutindo um banquinho de madeira que demonstra sinais de cansaço constrói-se um repertório de novos automatismos, a técnica faz-se corpo nos sete jovens alunos, uma segunda natureza é criada - uma técnica do corpo tem essa característica de ser sentida como da ordem do físicoquímico por quem a faz, é um habitus. Quando ele fala comigo, as suas expressões confundem-se com as bhavas codificadas que estão nas fotografias, numa parede da sala, acima das nossas cabeças, os seus olhos dançam nas órbitas com as sobrancelhas. Em Pangim, quarenta jovens entre os dezasseis e os vinte e dois anos apertam-se, caminham com um olhar misterioso e cheio, caem e levantam-se lentamente; impressionante ver quanto os corpos haviam já absorvido do primeiro para o segundo dia. Em Palakkad, a noite ameaça fugir para ocidente, sob a lua cheia os seis percussionistas e os quatro cantores que não estiveram juntos antes no palco, aquecem o climax do espectáculo; assistentes de cena e alguns espectadores afastam cadeiras e mesas, algo vai acontecer estou meio a dormir, meio acordado. A formação de um actor profissional de kathakali demora entre seis a oito anos, dependendo da profundidade e da extensão do repertório trabalhado, profundamente enraizado nos grandes épicos da literatura e nas estruturas da música 
clássica, alicerçado na iconografia indiana e relacionado historicamente com uma mundivisão do corpo que tem elementos comuns com o yoga e o kalaripayattu. "A personagem passa pela floresta e o que ela vê é estabelecido pelo intérprete" - diz Balasubramaniam; neste teatro codificado o actor encontra a sua liberdade na criação de um desempenho pessoal do repertório estabelecido. Em Pangim, dançamos o clássico "pilar de cinza"; no butoh como o conheço, a viagem, a natureza, as idades, o andrógino, a memória, o sonho, o monstro são alguns dos territórios onde cada um explora o seu butoh. 0 amplificador bate no vermelho, a música está altíssima, é inquietante, há uma luta em cena, os actores dançam vertiginosamente, fazem sons ululantes e avançam para a plateia; brincam e improvisam. Pergunto-me quanto pode a experimentação com o movimento no teatro contribuir para tomarmos consciência dos automatismos introjectados, para desimpedirmos certos fluxos anquilosados. Em Pangim, dançamos uma folha de papel que se desamarrota sozinha ao som do Carlos Paredes.

\section{4.}

Estou de volta a São Paulo, duas ruas acima de Goa, estou a escrever na cozinha. Pedi à Sandra que me escrevesse de Lisboa sobre a oficina e o que vimos, sem the mandar qualquer esboço do que já escrevera eu. Nos últimos momentos da oficina em Pangim, vimos um documentário sobre butoh e discutimos a oficina. Uma moça baixinha e de cabelo em frente aos olhos comenta com alegria que, pelo que the tinha sido exposto até ali, poderia ver dança em quase toda a parte. Um professor de liceu que estava presente observou que o impressionara a concentração e como cada diferença se destacava na simplicidade.

Comentou-se quanto o butoh estava por definir por cada um, falámos sobre umas gravuras da Vieira da Silva que estavam no corredor, filmes de fantasmas, e Bollywood, o bharatanatyam, o Teatr ${ }^{1}$. Transcrevo do texto da Sandra:
"Durante o meu percurso artístico, eu perguntei-me sobre as relações entre o teatro ocidental e o teatro oriental. Procurei explorar técnicas do teatro oriental, que experienciara, no estudo de textos dramáticos ocidentais: Posso aproximar-me com butoh de Tchekov ou de uma tragédia antiga? 0 que encontro quando trabalho Shakespeare ou Heiner Müller utilizando a técnica Suzuki? Como fazer renascer no teatro contemporâneo a ideia de ritual, de cerimonial, de celebração, de festa, de sagrado, de metamorfose, do inumano?" Sinto o butoh como uma possibilidade de intensificação e um espaço liso entre géneros, encontro de múltiplas singularidades. Lembro quanto a formação de actores e o teatro ocidental foram inspirados pelas práticas artísticas e espectaculares orientais, releio Pour en finir avec le jugement de dieu de Antonin Artaud, visito o trabalho da brasileira Lygia Clark. A Índia, agora, aumenta as minhas suspeitas de que o contacto com o outro pode-nos revelar possibilidades do que poderiamos ser. E também há uma série de afinidades portuguesas com o sul. "Todas estas inquietações aumentaram quando fiz a minha recente viagem de trabalho à İndia. Aí, fui surpreendida pela severidade, a beleza, a exigência, a honestidade e a generosidade quando conheci o kathakali. 0 fazer artístico não pode ser considerado um luxo desnecessário, que tal colocá-lo na roda dos alimentos?"

\section{Nota sobre as imagens}

A sequência das imagens apresenta diferentes episódios do Mahabharata trabalhado por Irathakulangara Rama Varrior: (1) explicação da simbologia dos movimentos; (2) momento de abertura da representação; (3) inicio da representação de Arjuna, famoso arqueiro e o terceiro principe Pandava; (4) Arjuna na busca da perfeição no uso do arco; (5) o deus Shiva disfarçado de caçador da floresta; (6) a deusa Parvathi disfarçada de mulher de caçador e, à esquerda, o deus Shiva; (7) antes do duelo entre o deus Shiva e Arjuna, depois deste último ter morto um javali; (8) a deusa Parvathi e o rei Duryodhana, depois de o deus Shiva ter castigado Arjuna pelo seu egotismo.
"Teatr" é um género teatral especifico de Goa que, segundo alguns, parece descender da revista à portuguesa. 